\title{
DESENVOLVIMENTO PROFISSIONAL DE PROFESSORAS ALFABETIZADORAS
}

\author{
LILIAMAR HOÇA \\ https://orcid.org/0000-0002-9650-0215 \\ Universidade Cesumar. Rede Municipal de Ensino de Curitiba
}

RESUMO Este trabalho teve como objetivo compreender o desenvolvimento profissional de professoras alfabetizadoras. A pesquisa utilizou a metodologia de história de vida e formação, com base em Josso (2010), utilizando narrativas de histórias de vida e formação, realizadas com quatro professoras alfabetizadoras de escolas municipais, em tempos diferentes da profissão. Os dados foram organizados e categorizados a partir da análise de conteúdo descrita por Bardin (2011), revelando os seguintes elementos constitutivos do desenvolvimento profissional de professoras alfabetizadoras: os laços de parentesco como primeiras forças a impulsionar a escolha pela profissão; as forças de trabalho do magistério que se constituiu como atividade feminina; laços geracionais, estabelecidos com alunos ao longo da trajetória profissional; laços profissionais que possibilitam transformações no fazer do professor; processos formativos que se constituem como laços contextuais da profissão constituídos nas e pelas relações estabelecidas com o grupo de trabalho, produzindo os conhecimentos da professora alfabetizadora e marcando momentos de transformação no desenvolvimento profissional. Os elementos analisados encaminham para a compreensão do desenvolvimento profissional de professoras alfabetizadoras como um processo interlaçado pela prática, formação para o exercício do magistério e pelas aprendizagens representativas do momento histórico e social da educação, que originam "laços" que passam a constituir o processo.

Palavras-chave: Desenvolvimento Profissional. Histórias de vida. Professoras Alfabetizadoras.

\section{ABSTRACT \\ LITERACY TEACHER'S PROFESSIONAL DEVELOPMENT}

This research paper seeks to understand the professional development of literacy teachers. The methodology was life stories and education based on Josso (2010), with narratives about life stories and education were conducted with four literacy teachers of local schools, each one at a different time of the profession. The data were 
organized and categorized from the content analysis described by Bardin (2011), revealing the following constitutive elements of the professional development of literacy teachers: kinship ties as the first ones to drive the choice for the profession; teaching work forces that constitute it as a female activity; generational ties, established with the students through a teacher's career; professional ties, which enable transformations in the teacher's act; the formative processes that are constituted as contextual ties of the profession, established in and by the relationships created on the work groups, creating knowledge and moments of transformation for the literacy teachers' professional development. The elements studied lead to the understanding of the literacy teacher's professional development as a process intertwined by practice, training for teaching and the representative learning of the historical and social moment of education, originating certain "bonds" and becoming, themselves, the process.

Keywords: Professional Development. Life stories. Literacy teachers.

\section{DESARROLLO PROFESIONAL PROFESORES DE}

\section{ALFABETIZACIÓN}

Este trabajo tuvo como objetivo comprender el desarrollo profesional de los maestros de alfabetización. La investigación utilizó la metodología de historia de vida y capacitación, basada en Josso (2010), utilizando narraciones de vida e historias de capacitación, realizada con cuatro maestros de alfabetización de escuelas municipales, en diferentes momentos de la profesión. Los datos se organizaron y categorizaron según el análisis de contenido descrito por Bardin (2011), que revela los siguientes elementos que constituyen el desarrollo profesional de los maestros de alfabetización: los lazos de parentesco como las primeras fuerzas para impulsar la elección de la profesión; la fuerza laboral de la profesión docente que se ha constituido como una actividad femenina; vínculos generacionales, establecidos con estudiantes a lo largo de su trayectoria profesional; vínculos profesionales que permiten transformaciones en el trabajo del profesor; procesos formativos que se constituyen como vínculos contextuales de la profesión constituida en y por las relaciones establecidas con el grupo de trabajo, produciendo el conocimiento del maestro de alfabetización y marcando momentos de transformación en el desarrollo profesional. Los elementos analizados conducen a la comprensión del desarrollo profesional de los maestros de alfabetización como un proceso entrelazado por la práctica, la capacitación para el ejercicio de la enseñanza y el aprendizaje que representa el 
momento histórico y social de la educación, que originan "vínculos" que comienzan a constituir el proceso.

Palabras clave: Desarrollo profesional. Historias de vida. Profesores de alfabetización.

\section{Introdução}

O tema desenvolvimento profissional dos professores apareceu na literatura norte-americana por volta dos anos 80 do século XX. Pesquisadores como Fenstermacher e Berliner (1985), preocupados com questões sobre qualidade de ensino, investigaram as práticas dos professores e, a partir das análises, perceberam que modificações no sistema educacional perpassavam pelas concepções de como ensinar, por habilidades e oportunidades de aprendizagem dos professores na trajetória profissional. Diante disso, os referidos autores caracterizaram essas oportunidades e aprendizagens como um processo de desenvolvimento na profissão.

Igualmente, Marcelo Garcia (1999), em investigações sobre formação de professores, inserção profissional e professores iniciantes, evidenciou que as especificidades da tarefa de ensinar já não poderiam ser explicadas como atividades mecanicamente aprendidas pelos professores em um determinado período de formação. Para o autor, trata-se de um conjunto complexo de habilidades, saberes específicos e sensibilidade dos docentes em relação aos sujeitos com os quais trabalham, atribuindo à docência o caráter de profissionalidade. Como preceitua o mencionado autor, esse conjunto não é estático, mas contínuo, dinâmico, inter-relacionado às questões de formação e condições de exercício da profissão que vão permitindo ao professor desenvolver-se profissionalmente.

O desenvolvimento profissional dos professores tem sido, nas últimas duas décadas, tema central de discussões entre educadores e pesquisadores, pois o termo permite refletir sobre as transformações ocorridas na vida profissional dos professores. Assim, discutir a temática acerca de desenvolvimento profissional de professoras alfabetizadoras é um processo de reflexão sobre o modo como a professora alfabetizadora foi se constituindo com necessidades, dificuldades e expectativas. Na constituição dos elementos do desenvolvimento profissional, vale ressaltar as palavras de Nias (1991, p. 15): “O professor é a pessoa; e uma parte importante da pessoa é o professor", pois as professoras são "sujeitos históricos", constituídas por uma cultura, com padrões colocados socialmente, experiências e antagonismos.

No processo do desenvolvimento profissional, os professores necessitam da inserção em investigações e reflexões sobre a prática, tanto individual como coletivamente, a fim de que possam rever, ampliar ou reorganizar os conhecimentos sobre projeto pedagógico, os componentes curriculares, os encaminhamentos metodológicos, o contexto em que realizam o trabalho, reconhecendo os valores que estão subjacentes. Como afirmou Day (2001), a atualização de conhecimentos e estratégias oportunizará o repensar da organização da sala de aula, do processo ensino e aprendizagem, da avaliação.

Os professores são responsáveis pelo próprio desenvolvimento profissional ao longo da carreira, mas não o fazem sozinhos. Gestores institucionais e em diferentes esferas governamentais precisam planejar ações de formação, pois, ainda segundo Day (2001, p. 17), “[...] os professores não podem ser formados (passi- 
vamente). Eles formam-se (activamente)". No processo de formação continuada, os professores realizam as escolhas de forma planejada, por iniciativa própria ou entre as ofertas dadas pela instituição ou aquelas definidas/ patrocinadas pelos gestores.

Day (2001) preconizou que outro elemento a ser considerado em relação ao trabalho docente e ao desenvolvimento profissional é a dose alta de trabalho emocional despendida no ensino, considerando os compromissos assumidos pelos professores tanto na sala de aula como nas tarefas burocráticas, nas relações estabelecidas com outros docentes, com gestores e com os alunos, além da concentração de energia no próprio trabalho. Essa carga emocional impacta nas relações dentro e fora da escola, nas expectativas quanto ao desempenho dos alunos e na reflexão sobre a prática e a aprendizagem do professor.

No contexto das investigações sobre desenvolvimento profissional, Marcelo Garcia (2009) o apontou como um processo contínuo, evolutivo, de modo que as experiências advindas da formação docente, da sala de aula e dos contextos organizacionais das instituições educacionais contribuem para sua caracterização.

Considerando as que a prática dos professores não muda do dia para a noite, de uma semana para outra, de um encontro de formação para outro, mas pode se modificar quando há um acompanhamento da prática pedagógica efetiva do professor, que leva à aprendizagem, à apropriação de conhecimentos e à reflexão sobre os mesmos, esse trabalho apresenta o resultado da pesquisa realizada no doutorado em Educação, com o objetivo de compreender o desenvolvimento profissional de professoras alfabetizadoras, considerando a escolha pela alfabetização, experiências docentes, conhecimentos, necessidades, dificuldades, no sentido de definir os elementos constitutivos desse processo.
Para a coleta de dados, foi utilizada a composição de narrativas de vida, a partir da abordagem dada por Josso (2010), com quatro professoras alfabetizadoras da Rede Municipal de Ensino (RME) da cidade de Curitiba, que, em seus tempos/espaços, trouxeram para o contexto da pesquisa elementos que dão voz aos percursos da trajetória docente e ajudam a desvelar o desenvolvimento profissional de professoras alfabetizadoras.

As profissionais foram identificadas com pseudônimos de escritoras brasileiras: Rachel de Queiróz, Cora Coralina, Cecília Meireles e Clarice Lispector, mulheres que, cada uma a seu tempo, usaram a escrita e a leitura para provocar, fazer rir, emocionar, descrever e compreender as relações sociais, assim como as professoras alfabetizadoras entrevistadas.

A organização e categorização dos dados da pesquisa foram realizadas pela análise de conteúdo, utilizando as considerações de Bardin (2011) e articulando com situações colhidas dos depoimentos escritos. Foram estabelecidos os seguintes indicadores para guiar a leitura e análise das narrativas: alfabetizarse (marcas possiveis); opção pela profissão; acontecimentos pessoais, profissionais, contextuais que influenciaram a trajetória profissional; tornar-se alfabetizadora (as necessidades e dificuldades).

Os dados da pesquisa fizeram emergir os laços e a malha do desenvolvimento profissional de professoras alfabetizadoras, com os quais a professora sustenta fazeres, ideias, concepções, crenças, valores, experiências.

\section{Histórias de vida, formação e desenvolvimento profissional de professoras alfabetizadoras}

Ninguém começa a ser educador numa certa terça-feira às quatro horas da tarde. Ninguém nasce educador ou marcado para ser educador. 
A gente se faz educador, a gente se forma, como educador, permanentemente, na prática e na reflexão sobre a prática. (FREIRE, 1991, p. 58)

As palavras do autor revelam que ser professor é um movimento de formação e transformação a cada período de vida e de trabalho, uma ação dinâmica e permanente, na qual estão envolvidos elementos sociais, culturais, políticos, éticos e humanos, considerando diferentes tempos/espaços e seus interlocutores.

Freire (1991) nos diz que certas preferências podem até aparecer na infância, como anunciadores de formas de dizer e fazer as coisas, mas serão as relações sociais estabelecidas com diversas pessoas e grupos - a quem comunicamos e somos comunicados com ideias, sentimentos, vontades, emoções, necessidades, dificuldades, em diferentes tempos e espaços - que verdadeiramente se constroem e reconstroem a vida pessoal e profissional.

As ideias de formar e formar-se destacadas por Freire (1991) forneceram a sustentação para o princípio desenvolvido por Hoça (2017) sobre o desenvolvimento profissional da professora alfabetizadora como um processo constituído por histórias de vida, formação para o exercício do magistério, formação continuada e pelas aprendizagens representativas do momento histórico e social da educação, além dos conhecimentos, necessidades, dificuldades, oportunidades e experiências profissionais em diferentes contextos de atuação.

O processo de desenvolvimento profissional dos professores é complexo e se assemelha a um caleidoscópio, no qual as discussões e temas em torno da temática se constituem como as diversas partículas, combinações, paridades e sobreposições que podem ser observadas, analisadas, mas que formam um todo.

Para alcançar o objetivo proposto para a pesquisa, empregou-se as narrativas de história de vida e formação, como possibilidade metodológica para a análise do desenvolvimento profissional. Para que os sujeitos participantes da pesquisa realizassem a composição das narrativas de vida, utilizou-se como fundamentação a abordagem dada por Josso (2010), que estabeleceu uma sequência metodológica inicial subdividida em quatro etapas: aproximação; construção da narrativa de história de vida pessoal e profissional; exploração oral das narrativas; leitura.

Para a construção das narrativas, foram realizadas sessões, como pressupôs Josso (2010), com um roteiro relacionado aos processos vividos na alfabetização, formação, trajetória profissional, acontecimentos pessoais, profissionais e contextuais que influenciam a atuação docente, o início na função, a permanência, os conhecimentos e as demandas da professora alfabetizadora.

De acordo com Josso (2010), o roteiro e o tempo dados para a realização da sessão são os elementos necessários para a construção da narrativa oral, pois se trata de uma preparação individual, na qual a pessoa busca na memória tudo aquilo que é considerado significativo no percurso de vida. Como a autora afirmou, os trabalhos do tipo história de vida caracterizam-se por assumir a autopoiese, sentido de uma produção sobre si, explorada, revisitada, reconstituída e analisada a partir dos caminhos percorridos, acontecimentos, explorações, atividades.

As participantes do estudo foram quatro professoras alfabetizadoras da RME da cidade de Curitiba, que durante as narrativas, deram voz aos percursos da trajetória docente e ajudaram a desvelar o desenvolvimento profissional de professoras alfabetizadoras.

A primeira professora a realizar a narrativa foi Rachel, curitibana, nascida em fevereiro de 1956. Uma menina tímida que, logo no início da escolarização, justamente na primeira série, teve a saúde abalada e ficou afastada da 
escola, provocando dificuldades em seu processo de alfabetização.

A professora é graduada em Letras pela Universidade Tuiuti do Paraná (UTP) e mestra em Ciências da Educação em Portugal. Ingressou na RME de Curitiba em 1974, após a conclusão do Magistério em escola pública. Contou que, no início da carreira, não tinha pretensão de fazer faculdade e só iniciou o estudo superior porque precisava aprender mais sobre aquilo que iria ensinar, ou seja, a Língua Portuguesa. Rachel resolveu investir em sua formação acadêmica, o que considerou um marco no desenvolvimento para a profissão.

A segunda professora a realizar a narrativa foi Cora, que declarou, já no início da conversa, que achava que não tinha algo interessante para contar, que provavelmente existiam outras profissionais com mais condições de relatar sua vivência.

Foi necessário argumentar que, para a pesquisa sobre desenvolvimento profissional, ela teria muitas histórias e uma representativa, pois a sua participação em um estudo exploratório trouxera indicativos do trabalho desenvolvido como professora alfabetizadora. Nesse momento, foi necessário buscar a professora alfabetizadora que se encontrava na sala de aula, que se autorizasse a pensar, a deixar espaços à imaginação e ao prazer de ensinar, a fazer visivel uma produção que era invisivel para muitos olhares, como já afirmaram Acevedo e Volnovich (1991).

Na narrativa, Cora relata que seu processo de alfabetização foi doloroso, pois a primeira professora não foi receptiva e a assustou muito, a ponto de fazê-la chorar para não ir à escola. Começou a trabalhar em escola particular com 15 anos e ingressou na RME em 1990, como professora alfabetizadora, depois foi convidada a ser formadora de alfabetizadores e retornou à escola após um período, por sentir que o trabalho como formadora não a completava como a sala de aula e os alunos. Cursou a graduação em Formação de Professores Educação Infantil e Séries Iniciais e pós-graduação em Modalidades de Intervenções no Processo de Ensino e Aprendizagem. Cora contou que só fez a graduação por uma exigência da própria RME, para buscar referenciais que pudessem explicar a sua prática como alfabetizadora. Sua narrativa é repleta de momentos nos quais as lágrimas se sobrepuseram às palavras.

A terceira alfabetizadora, sob o pseudônimo Clarice na pesquisa realizada, ingressou na RME no ano de 2013, mas atuava como professora desde 2005. Fez Pedagogia na sua cidade natal e, depois, pós-graduação em Gestão. A narrativa desse período trouxe as experiências com a cultura diversa para o seu desenvolvimento profissional.

Clarice relatou, com entusiasmo, as atividades que desenvolveu com seus alunos e com as famílias. No final, surpreende-se, dizendo que só percebeu que tinha uma história para contar depois que escreveu e leu tudo novamente.

A quarta professora alfabetizadora que realizou a narrativa foi Cecília, professora alfabetizadora da RME desde 2007, ano em que ingressou na rede após um período de trabaIho em outra área. Ex-aluna da escola municipal pertencente à RME, Cecília lembrou com carinho dos espaços da instituição utilizados pelas crianças para realização do lanche e das brincadeiras.

Cinco anos depois de cursar bacharelado em Informática, fez Normal Superior e Pedagogia. Em seguida, começou a atuar como professora de uma segunda série na escola em que ela mesma fora alfabetizada. Sua narrativa destacou o modo como organizava as atividades seguindo determinado modelo metodológico e apresentou as dificuldades da professora iniciante com uma turma em processo de 
alfabetização, dúvidas, conflitos e ausência da ajuda de outro professor experiente.

Para organização dos dados a partir das narrativas, utilizou-se a marcação de palavras e frases significativas, que correspondiam aos indicadores propostos. Estes apontaram para elementos que se constituem como conteúdo e forma no desenvolvimento profissional, e com a ajuda dos referenciais apresentados por Josso (2010), estabeleceram-se laços de parentesco, geracionais, profissionais e laços contextuais da profissão.

Segundo essa autora, no trabalho de pesquisa com história de vida alguns desses "nós" são evocados continuamente, enquanto outros aparecem em momentos específicos no percurso da formação e, gradativamente, são esquecidos.

Para composição da análise, percorreu-se muitas vezes as narrativas e os depoimentos, destacando tempos significativos das trajetórias, utilizando como ponto de apoio os momentos charneiras, que Josso (2010) define como períodos de vida nos quais determinados acontecimentos são marcantes a ponto de estabelecerem passagens para uma nova etapa, sendo caracterizados pela autora como uma espécie de divisores de águas.

Rachel, Cora, Clarice e Cecília revelaram nas narrativas de vida e formação momentos charneiras que marcaram suas vidas enquanto crianças, estudantes, mulheres, profissionais e as direcionam em diferentes tempos/espaços à tomada de decisões, marcando determinadas etapas de vida (tanto na esfera pessoal quanto profissional).

$\mathrm{Na}$ leitura das narrativas, buscando acontecimentos que marcaram o desenvolvimento profissional das professoras, foram encontradas referências a determinadas pessoas que, nas histórias de vida, desempenharam papéis muito singulares.

Segundo Josso (2006, p.376), ao revisitar- mos nossa história de vida para dela retirarmos "[..] o que o que sabemos sobre nós mesmos e nosso ambiente humano e natural [...]", determinados vínculos com pessoas da família e instituições de ensino - nas quais estudamos e trabalhamos - começam a aparecer e a influenciar a forma de agir, de comportarse, de pensar a própria escolha profissional e pessoal. Não são modelos padronizados, mas formadores, concebidos pela dinâmica do contexto social e que se modificam com o tempo.

Esses laços são de parentesco, geracionais, transgeracionais, profissionais, religiosos e espirituais, e cada um é capaz de ligar, desligar e religar acontecimentos, pessoas, grupos e a si mesmo, com intensidades diferenciadas e, por isso, estão enlaçados à vida profissional formando uma verdadeira malha. Como afirmou Josso (2006, p. 379): “Nós estamos na vida porque existimos mediante uma multiplicidade de laços simples ou complexos".

Ainda de acordo com Josso (2006), os laços de parentesco são evocados com frequência nas narrativas, aparecendo como estruturantes ao longo do relato ou em determinados momentos. São originados a partir do nascimento ou aqueles constituídos em relações de alianças. O que chama atenção é a força “[...] de lealdade e de fidelidade que engendram e que se manifestam não apenas na preservação das relações mais ou menos ritualizadas, mas igualmente nas convicções adotadas" (JOSSO, 2006, p. 376).

$\mathrm{Na}$ fase adulta, já desenvolvendo algum tipo de trabalho, estabelecem-se os laços profissionais, que ocupam espaço importante na vida dos sujeitos, justificados pelas relações sociais estabelecidas em decorrência da convivência no ambiente de trabalho, da aprendizagem profissional, das diferentes negociações que acontecem para o desenvolvimento das atividades do trabalho. 
Rachel, Cora e Clarice relataram fatos marcantes para elas no período inicial de alfabetização, relacionados aos comportamentos diferenciados das suas professoras, traduzindo as atitudes iniciais em experiências escolares contraproducentes e estabelecendo na profissão princípios que orientaram a relação com os alunos. São laços que foram estabelecidos com diferentes professores, em diferentes tempos, com os alunos e que marcam o desenvolvimento profissional das professoras.

Os laços de parentesco evidenciados pelas alfabetizadoras Cora, Clarice e Cecília enfatizam a presença familiar de pai, mãe e irmãs. Nos relatos de Cora e Cecília, as relações familiares marcam um determinado período de vida e, em Clarice, os laços estabelecidos com a mãe perpassam toda a narrativa. Destaca-se relatos que ilustram a constatação:

Cora: Não sei se já saí alfabetizada da primeira série, mas minha mãe estava sempre me ajudando a estudar. Enquanto ela fazia almoço, ia ditando palavras e eu as escrevia no papel de embrulho da carne. Certa vez, cheguei feliz da vida em casa depois de ter acertado todas as palavras do ditado. Entrei falando: Mãe, você sabia todas as palavras que iam cair na prova! A opção pela profissão aconteceu quando eu tinha oito ou nove anos e uma das minhas irmãs mais velhas ingressou no magistério. Eu adorava vê-la escrevendo e fazendo aqueles diários tão caprichados; quando ela descartava algum desenho ou atividade, eu pegava e guardava.

Cecilia: Nessa época, minha mãe já era professora e foi ela quem me falou do concurso. Ela havia cursado o Magistério em 1990, quando eu já tinha 10 anos de idade, então ingressou bem mais tarde na profissão.

Clarice: Minha mãe, professora com uma rotina cheia, chegava cansada e precisava fazer a tarefa com a filha, que estava chorando porque a professora brigou ou disse que ela não sabia fazer.

Clarice: Ao terminar o Ensino Fundamental, fui para uma escola estadual bem próxima e, logo depois, decidi fazer o Curso Normal. Quando contei isso para minha família, minha mãe me orientou muito, contando todas as 'verdades' sobre o que é ser professora.

Os relatos ilustram a preposição de Josso (2006) de que são laços que transcorrem as histórias com influência em convicções dos sujeitos. Em Rachel, esses laços são breves e utilizados para justificar a escolha realizada para iniciar o trabalho docente, logo após a formação no curso de magistério. A família, primeiro núcleo social das pessoas, marca o aprendizado da leitura e da escrita e, posteriormente, a escolha pela profissão para essas professoras.

$\mathrm{Na}$ trajetória escolar das entrevistadas, o processo de alfabetização se constituiu como o momento charneira, caracterizado pelo sentimento de rejeição, insegurança e dificuldades para aprender a ler e a escrever. As histórias de vida examinadas trazem lembranças da primeira alfabetizadora como pessoa com a qual elas não conseguiram estabelecer um vínculo afetivo e, em seguida, recordavam de professoras alfabetizadoras acolhedoras, sensiveis às dificuldades que apresentavam.

Há trechos marcados nas histórias de vida das professoras alfabetizadoras destacados para ilustrar a proposição levantada, denominados de "Momento $A$ " os relatos que evidenciam a dificuldade na alfabetização; “Momento B" os que denotam a superação em relação processo de alfabetização, com apoio de professores ou familiares:

\section{Rachel:}

Momento A: Era a primeira vez que eu entrava na escola, cercada por todas aquelas crianças, sem nenhum rosto familiar. Eu tinha consciência de que eu não sabia muito na escola. Sempre tive a sensação de ser deixada de lado. Não sei em qual cadeira me sentava, se tinha mala, se ia sozinha até lá. Nada, nada mesmo. Apaguei todas as informações desse período como uma forma de defesa.

Momento B: [...] Eu ainda estava doente, não po- 
dia acompanhar todas as aulas e, quando estava presente, entendia muito pouco do que a professora fazia. Mas essa professora tinha, dentro de si, o verdadeiro sentido do que era ensinar. Ela me passou uma confiança que eu não tinha encontrado na educação até aquele momento. Seu nome era Creusa. Foi só no quarto ano que, finalmente, tive uma professora maravilhosa que conseguiu me enquadrar como aluna. Foi ela, naquele ambiente da escola pública, que se deu conta do que era possivel fazer para que eu conseguisse assimilar tudo e saísse de lá como uma boa aluna.

\section{Cora:}

Momento A: A professora não foi muito receptiva e acho que não queria nem um pouco estar ali. Não demonstrou nenhum carinho ao nos receber, xingava os alunos de "macacos" se não conseguia o domínio da turma, era grosseira, empurrava e socava as crianças na cadeira. Eu morria de medo de esquecer, de levar a tarefa errada e ela acabar brigando comigo também. Comecei a acordar às 5 da manhã, chorando $e$ pedindo para não ir à escola. Se ela passava tarefas para casa, eu simplesmente surtava. Meu comportamento em relação à escola preocupou bastante meus pais.

Momento B: Nos anos seguintes (graças a Deus), tive professoras maravilhosas, que guardei na memória com carinho e, anos depois, se tornariam minhas colegas de profissão na rede.

\section{Clarice:}

Momento A: Tive uma dificuldade imensa para me encaixar entre os colegas, nos espaços, com a professora. Ainda posso ver o rosto dela e o jaleco com seu nome: Karina. Ela me fazia pensar que não era uma aluna querida ou tão boa quanto as demais crianças que tinham frequentado a escola anteriormente. Eu não me sentia acolhida naquela turma, acabei recebendo o apelido de manteiga derretida; já tive meu nome escrito no quadro e sei que não é uma lembrança boa.

Momento B: Na segunda série, voltei para a escola em que minha mãe trabalhava. A partir daí, as coisas mudaram: eu não tinha problema de adaptação, gostava das professoras, dos colegas, estava lendo.
Para as professoras alfabetizadoras, o início da escolarização é dado como período de exclusão e insegurança. Apoiam-se em expressões emotivas e revelam determinadas posturas utilizadas em sala de aula, características de concepções que buscaram sustentar a ordem e a relação professor-aluno por meio de práticas disciplinadoras de corpos, mesmo que isso custasse o sentimento de humilhação cultivado pela criança.

No percurso das narrativas, emergiram os laços geracionais estabelecidos por Rachel, Cora e Clarice, ainda alunas, destacando as relações professor-aluno, que as fizeram narrar situações de controle da disciplina e caracterização do rendimento escolar, sentindo-se inicialmente recusadas por suas respectivas professoras. Foram nas relações de afetividade que essas alfabetizadoras encontraram sustentação para continuar a escolaridade, o que leva a refletir sobre a imagem socialmente institucionalizada da professora alfabetizadora como uma figura que traduz o modelo de afeto, de admiração e crença pedagógica.

Os relatos selecionados sustentam a proposição dos laços geracionais estabelecidos no percurso profissional, incluindo o indispensável afeto que a professora alfabetizadora carrega:

Rachel: Eu amava aquelas crianças. Chorava com elas, dava risada com elas e conseguia, inclusive, aproximar as famílias. A primeira turma que tive foi um sucesso, com $100 \%$ de alfabetização. Eu percebi isso em setembro, durante os conselhos de classe. [...] eu decidi que, mesmo com a miséria de dinheiro que eu recebia e sem saber o quanto aquilo custaria, iria economizar e comprar um livrinho para cada um. Escrevi uma dedicatória sobre 'agora que você já sabe ler...', coloquei em um belo papel de presente e entreguei emocionada, porque tinha certeza de que eles terminaram o ano sabendo ler e eu tinha sido a responsável.

Cora: Tive, então, uma turma de pré com trinta 
alunos. $O$ ano foi maravilhoso, produtivo, daqueles que você nem quer que acabe. A pedagoga certa vez comentou: - Teus alunos devem pensar: 'O que será que a professora vai trazer hoje?'. E as pessoas que entravam naquela sala sempre perguntavam: '- É mesmo uma turma de pré que fica aqui?' Guardo até hoje as fotos dessa turma. Graças a ela e a uma visita que recebi da Pedagoga do Núcleo em minha sala - em que meus alunos afoitos foram mostrar como estávamos trabalhando as obras de Monet na escola.

Clarice: Aqui em Curitiba, quando passei no concurso público municipal, fui contratada para a Educação Infantil, mas precisaram me remanejar para o ensino fundamental, na mesma escola. Achei que teria problemas por ser a professora nova, aquela com que as crianças não estavam muito habituadas. Mas a turma me mostrou que o tempo usado no início do ano para conhecer as crianças e as famílias acaba sendo proveitoso lá na frente.

O imperativo do afeto (ABRAMOWSKI, 2010) tem um espaço firmado na formação e na prática da professora alfabetizadora, ocupando lugar na formação dos professores e no desenvolvimento profissional, inclusive justificando a escolha de turmas de alfabetização. De acordo com essa autora (2010, p. 53), os afetos docentes pelos alunos: “[...] não são naturais, espontâneos, instintivos, universais, eternos e nem imutáveis - mas históricos, cambiantes, construídos e aprendidos".

Segundo Abramowski (2010), os professores aprenderam, na formação, os exercícios de moderação de voz, postura, que consistiam em expressões manifestadas quando se sentiam zangados ou aborrecidos - como, por exemplo, não levantar o tom de voz, ignorar as provocações e tomar distância emocional satisfatória sem extinguir o caráter afetivo de sua postura.

A essa questão, adicionam-se outros elementos contextuais e históricos importantes para compreender as mudanças em relação aos afetos docentes: abertura das escolas normais para atender à formação de moças e rapazes indicados ao exercício do magistério, aumento da demanda escolar e entrada expressiva da mulher no magistério, difusão dos conceitos de aprendizagem com base na Psicologia do desenvolvimento humano.

Outro laço geracional efetivado no percurso profissional das professoras alfabetizadoras foi constituído pelos esforços pedagógicos realizados pela professora, que buscava estratégias para realizar um ensino que atendesse à proposta pedagógica e caminhasse para o atendimento às necessidades educacionais dos estudantes.

$\mathrm{Na}$ narrativa de Rachel, encontram-se os alunos que alfabetizou na então chamada primeira série e os estudantes que também influenciou na perspectiva de leitura da palavra para fazê-los ler o mundo, como já explicitou Paulo Freire (1991). A professora Rachel relatou:

Rachel: A primeira turma que tive foi um sucesso, com $100 \%$ de alfabetização. Eu percebi isso em setembro, durante os conselhos de classe que mantinham sempre o mesmo discurso: 'Se quinze alunos vão reprovar, vamos acelerar para, pelo menos, cinco deles passarem. Cuidado com a média: $x 1, x 2, x 3$ e x4, nos bimestres finais'. Meus alunos não precisavam disso. Estavam bem, bem demais.

As professoras Cora e Cecília, que iniciaram a profissão na educação infantil e exerceram as atividades de professoras alfabetizadoras na RME de Curitiba, demonstraram nas narrativas as preocupações com o trabalho pedagógico, a partir da avaliação e relação com os alunos:

Cora: A escola aplicava a reprovação anual, mas, ao final daquele ano, eu tive apenas dois alunos que não conseguiram se alfabetizar e outro que foi avaliado para a classe especial. Aí, sim, colhi os frutos do meu trabalho, vendo meus alunos crescerem e se alfabetizarem. Até hoje, sintome orgulhosa por ter feito parte de suas vidas e muito grata por ter aprendido tanto com eles. 
Clarice: Tive a sorte de cair em um segundo ano, pude acompanhar bem o desenvolvimento da minha turma e devo dizer que foi fantástico, melhor do que eu esperava. Achei que teria problemas por ser a professora nova, aquela com que as crianças não estavam muito habituadas. Mas a turma me mostrou que o tempo usado no início do ano para conhecer as crianças e as famílias acaba sendo proveitoso lá na frente.

A narrativa de Cecília indica que os laços geracionais se estabeleceram com conflitos na relação professor-aluno, considerando que inicou com uma turma com determinadas especificidades e, na prática, estava iniciando as atividades no magistério:

Cecília: Eu passava o conteúdo no quadro e eles conseguiam copiar, avançando na medida do possivel. Um desses alunos, chamado Lucas, marcou-me até hoje. Ele tinha laudo, não lembro o que era, mas se colocou como meu defensor. Era ativo, um foguete, mas se alguém fizesse alguma coisa para mim, ele levantava da carteira e ia lá tirar satisfação com a criança que tinha feito birra, levantado a voz ou coisas do tipo.

É interessante destacar que laços geracionais estabelecidos com os alunos nas histórias de vida coincidem com a inserção na profissão, período marcado pelas articulações com professores experientes, retomada de aprendizagens do período de formação inicial e preocupação com o saber ensinar e a disciplina da turma.

Esse período denota atenção dos gestores em diversos níveis (escola - sistema educacional), pois a atenção aos professores em início de carreira tem uma repercussão futura no desenvolvimento profissional, como informa Marcelo Garcia (1999).

Os laços profissionais dessas alfabetizadoras anunciaram que os profissionais que atuaram com elas, na escola ou em outros espaços, trouxeram aspectos singulares ao seu desenvolvimento profissional. Esses laços, como explica Josso (2006, p. 377), são muito evidencia- dos nas narrativas de vida porque "[...] o tempo passado no local de trabalho e os elos obrigatórios por meio dos quais esse tempo é tecido levam as múltiplas negociações e ajustes dessas ligações singulares". As ligações e relações estabelecidas levaram Rachel a evidenciar que as profissionais da escola a fizeram refletir sobre o papel da mulher professora:

Rachel: A escola da Prefeitura era bem dirigida $e$, por lá, tive uma das melhores experiências da minha vida. Emociono-me ao lembrar pessoas que me ensinaram profundamente e me marcaram no jeito de vestir, falar e como mulher. Eu comecei a pensar: 'Uma mulher pode ser assim, é isso que ela pode fazer'. Foram pessoas fantásticas. Uma equipe que mandava, fazia acontecer, acontecia, movimentava a comunidade. Quanto mais eu ficava naquele lugar, mais eu me empenhava na faculdade, mais eu entendia o que é ser professora.

Esse relato trouxe pistas sobre a importância de profissionais que, nas escolas, acompanham professores iniciantes e auxiliam com a experiência no entendimento dos procedimentos escolares, na busca e adequação de estratégias de ensino, visando à qualidade da aprendizagem. Na narrativa de Rachel, destacou-se o grupo de trabalho, que se empenhou no estudo da proposta pedagógica e na formação de outras professoras alfabetizadoras, enlaçando as atitudes profissionais em um determinado tempo/espaço.

0 relato de Clarice fez inferência ao profissional conhecido como coordenador pedagógico ou, no caso da RME de Curitiba, o pedagogo - profissional que acompanha, analisa e busca intervir no processo de ensino, de maneira que a proposta pedagógica e o currículo possam ser efetivados.

A pessoa do coordenador ou do pedagogo auxiliaram Cecília tanto na organização das atividades de sala de aula, quanto no processo de compreensão e trabalho com as famílias dos alunos: 
Cecilia: A coordenadora conseguiu construir uma equipe e uma experiência escolar maravilhosas. Até hoje, sinto-me influenciada por ela, por todas essas coisas positivas que ela fez. Depois dela, outra coordenadora marcante que eu tive foi aqui em Curitiba, quando precisei passar da Educação Infantil para o fundamental. Talvez eu até tivesse mais experiência em sala de aula do que ela, mas o que essa profissional trazia como gestora, em relacionamentos interpessoais, era indiscutivel. Quando fui remanejada do Infantil IV, com crianças de quatro anos, para um segundo ano do ensino fundamental, comecei a chorar em plena semana pedagógica. [...] Eu não queria, de jeito nenhum, sob hipótese alguma, tudo menos isso. Mas não tinha escolha. Era isso e acabou. [...] Os pais não aceitavam. [...] Foi aí que os conhecimentos em gestão da coordenadora me ajudaram muito e eu pude ver toda a sua indiscutivel capacidade. É engraçado. Ela tem idade para ser minha mãe, mas nos tornamos grandes amigas e eu a vejo como uma das peças fundamentais para o meu desenvolvimento. Sua ajuda ia de separar materiais para estudo a frases épicas para explicar e mudar minha forma de agir: 'Leia esse texto. Foi você que criou uma couraça com esses pais! Clarice Lispector, você está fazendo errado, tem que trazer os pais para você!! Foi graças a ela que, hoje, aqui na escola em que trabalho, não conheço um pai, mãe, tio ou avó que não goste de mim. Aprendi a lidar com as famílias com a ajuda dela, a quebrar a resistência que sempre tive e não deixar os estereótipos voltarem.

A presença das pedagogas e da docente foi marcante nesse relato, pois trouxe o grande desafio dos professores iniciantes, que passam a ensinar e também aprendem a ensinar com outros profissionais, como destacou Marcelo Garcia (1999), fazendo com que as relações estabelecidas possam tanto auxiliar no desenvolvimento, quanto produzir marcas que inevitavelmente proporcionam insegurança, contrariedade e geram mal-estar profissional:

Cecilia: Lembro que visitei a escola em uma terça-feira e, já no começo, ela me apresentou a professora Márcia, que também trabalhava com a segunda série. Nessa hora, apesar do frio na barriga por estar em uma nova escola, com novos alunos e equipe, senti que teria algum apoio dessa profissional.

As pessoas de referência percorrem todas as narrativas, como pontos influentes que orientam, apoiam, fazem observações sobre a prática e elevam a identidade das professoras. Portanto, a identidade do professor é um processo coletivo de construção de significados sobre o que é ensinar, onde, como e para quem ensinar, sobre o que e como aprendem aqueles a quem se ensina. Esse processo é legitimado pela sociedade em um determinado tempo/espaço, suscitando discursos característicos desse grupo como uma categoria profissional. Segundo Gatti (1996, p. 86), “[...] a identidade é fruto de interações sociais complexas nas sociedades contemporâneas e expressão sociopsicológica que interage nas aprendizagens, nas formas cognitivas, nas ações dos seres humanos".

As pessoas referenciadas nas histórias de vida e formação ajudaram a ligar, religar e desligar as ideias no contexto de formação dos professores, das experiências e da cultura, estabelecendo os laços que Josso (2006) apresentou como pontos determinantes que podem transformar ou até mesmo deformar o processo de desenvolvimento profissional. A partir das histórias de vida e formação das quatro professoras alfabetizadoras, foi possivel identificar que a escolha não é neutra. Os motivos subjacentes da profissão do magistério são as condições sociais, econômicas e de gênero, permeadas pela presença de laços parentais e geracionais que envolvem essas professoras em diferentes tempos.

Os relatos das professoras ilustram a afirmativa:

Rachel: Eu fui empurrada para o magistério porque me parecia a melhor maneira de ganhar dinheiro - e depressa. Nunca acreditei em fazer faculdade, não tinha uma aspiração do que eu 
gostaria de ser. Decidi que tinha que fazer o Curso Normal, terminá-lo e começar logo a trabalhar, para mudar a situação em que eu cresci.

Cora: A opção pela profissão aconteceu quando eu tinha oito ou nove anos e uma das minhas irmãs mais velhas ingressou no magistério. Eu adorava vê-la escrevendo e fazendo aqueles diários tão caprichados; quando descartava algum desenho ou atividade, eu pegava e guardava (pensando bem, acho que alguns ainda estão em uma gaveta - e pense que minha irmã já se aposentou).

Clarice: Ao terminar o ensino fundamental, fui para uma escola estadual bem próxima e, logo depois, decidi fazer o Curso Normal. Quando contei isso para minha família, minha mãe me orientou muito, contando todas as 'verdades' sobre o que é ser professora. Ver minha mãe lecionar encantava-me [...] Enquanto meu pai se enchia de orgulho desde o primeiro dia, minha mãe (mesmo estando feliz por mim) continuava a mostrar todas as faces da minha escolha. Falava muito da questão financeira. Quando tive a oportunidade de estagiar, percebi que queria estar entre os alunos. Eu estaria realizada, transformada e, se essa fosse minha decisão final, uma coisa estaria certa: eu também seria muito bem orientada.

Cecilia: Em julho de 2005, eu concluí o Magistério Normal Superior. Não lembro se foi logo depois ou no ano seguinte, mas apareceu um concurso da rede municipal. Resolvi fazer a prova, passei e fui tão feliz falar para o meu chefe do centro auditivo: '- Quero a minha conta, porque agora eu vou ser professora'.

Nessa época, minha mãe já era professora e foi ela quem me falou do concurso, mas eu mesma fui atrás do que eu queria.

Nesses relatos, existem indicativos de que a mulher pertencente à classe trabalhadora vê possibilidades de melhoria na condição de vida pelo exercício do magistério. Mesmo diante do cenário adverso de desvalorização social e econômica pelo qual o magistério foi condenado, as mulheres professoras buscam a identidade de trabalhadoras intelectuais. Segundo
Gatti e Barreto (2009), dois elementos oferecem aos professores um reconhecido estatuto social: o nível de escolarização necessária para o exercício profissional e os elementos legais regulatórios da profissão. As autoras destacaram que, além da importância econômica, o trabalho dos professores também tem papel central do ponto de vista político e cultural. 0 ensino escolar há mais de dois séculos constitui a forma dominante de socialização e de formação nas sociedades modernas e continua se expandindo.

Os acontecimentos econômicos, tecnológicos, políticos e a organização do modo de produção que marcaram a história alteraram de maneira substancial os padrões sociais. Também o avanço do capitalismo industrial a partir do século XIX nos países ocidentais colaborou para a mudança significativa na valorização e definições das profissões quanto ao gênero e classe social, adequando as exigências ideológicas do mundo industrializado. A professora nas escolas primárias marca o novo status social e profissional da mulher em diversos países do ocidente.

Na sociedade brasileira, tipicamente agrária, a condição social e cultural da mulher fez valer a figura humana afetuosa, frágil, de poucas ambições e com pouca instrução, a quem é dado o direito de aprender a cuidar do futuro esposo, filhos, casa e, entre as meninas de classes favorecidas, desenvolver o mando dos serviçais e não de ter uma profissão. Tal discurso ganhava muitos adeptos, considerando que "[...] as mulheres deveriam ser mais educadas do que instruídas" (LOURO, 2015, p. 446).

No contexto dos debates sobre a profissionalização docente na perspectiva do desenvolvimento profissional, a formação dos professores direciona-se para a aprendizagem permanente, que mobiliza as experiências profissionais, pessoais e conhecimentos para 
realizar a crítica reflexiva e a ética sobre a prática docente.

Os depoimentos de Rachel, Cora, Clarice e Cecilia evidenciaram como ingressaram na alfabetização e como permaneceram alfabetizadoras por tempos distintos, em relação aos laços geracionais que se articulam com os laços profissionais:

Rachel: $O$ que me levou para a alfabetização? A mesma necessidade que a escola tem desde sempre: empurrar a professora mais nova e bobinha para as turmas mais novas, as quais, segundo eles, também bobinhas. A diferença era que eu poderia até ser a recém-chegada, mas não tinha nada de boba, não tinha medo do trabalho e, muito menos, dos alunos.

Cora: $O$ meu primeiro trabalho como professora do município foi com aulas de Ciências, cobrindo as permanências em oito turmas. Em janeiro do ano seguinte, fiz um curso de Alfabetização $e$, no início do período letivo, tinha sido remanejada para outra escola. Eis que a pedagoga perguntou: 'Quem fez aquele curso de Alfabetização do Departamento da Secretaria de Educação, em janeiro?' Eu levantei o braço, entre as professoras. A pedagoga respondeu, sorrindo: 'Você vai amar a alfabetização'. E ela estava completamente certa.

Clarice: Na escola em que trabalho, a gente brinca que a direção nos proporciona a experiência de acompanhar a turma até o terceiro ano. Eu nunca tinha vivenciado essa escolha, essa oportunidade em outras escolas. Precisei trabalhar muito, pesquisar e entender as habilidades necessárias para ser uma professora de uma série diferente, em vez de ter uma turma diferente, mas que seguia um mesmo padrão de encaminhamento pedagógico.

Cecilia: Fui nomeada em fevereiro de 2007 e, na hora de escolher vaga no núcleo, optei por trabalhar na escola em que fui alfabetizada. A diretora era professora na época em que eu estuda$v a$, então, seria tudo tranquilo. A professora que eu substituiria iria sair de licença maternidade e só estavam aguardando alguém vir do concurso para assumir a turma. Era uma segunda série. Mas, diferentemente do que eu pensava, a experiência foi bem dificil.
De acordo com Marcelo Garcia (1999), o desenvolvimento profissional dos professores é parte constituinte do sistema educacional, influenciado pela confluência de processos determinados por instâncias oficiais e extraoficiais que marcam, com posicionamentos e conhecimentos, o fazer e saber fazer dos professores. Nesse sentido, a cultura institucional, entendida como conjunto de normas, princípios, processos de organização didática-pedagógica e formação, foi determinante para inserção das professoras participantes deste estudo como professoras alfabetizadoras.

No desenvolvimento profissional, o tempo, os espaços e as diversas experiências pelas quais passam os professores, tanto individuais quanto coletivas, influenciaram o comportamento diante de determinadas situações, gerando o ciclo de desenvolvimento profissional, como Hubermann (2007) denominou, caracterizado por fases que expressam atitudes, ideias e ações, frutos do desenvolvimento psicológico e social desse professor.

Nas narrativas de vida e formação, as atividades formativas foram apresentadas como referências para a prática pedagógica e marcos para os laços profissionais. São atividades com as quais as professoras se identificaram e que as permitiram sustentar o fazer de alfabetizadora. São ela: o curso de graduação; a gestão da escola como uma referência; os cursos de formação promovidos pela mantenedora; e cursos provenientes de políticas nacionais de formação de professores.

As atividades e gestão elencadas pelas professoras compõem a estrutura basilar de formação, isto é, foram formações que influenciaram em determinados tempos o saber, o fazer e o saber fazer dessas professoras, promovendo o desenvolvimento profissional.

A formação diz respeito à aprendizagem profissional do sujeito adulto em diferentes etapas, que iniciam com uma relação mais 
rígida com o conhecimento, necessitando de instruções detalhadas, referenciais concretos, indicadores de organização, ampliando gradativamente e estruturando outras etapas, chegando a um alto nível de desenvolvimento conceitual e abstração. Ao olhar as atividades de formação, se faz necessário considerar que os professores são sujeitos históricos, que constroem e reconstroem seus laços na sua história pessoal e profissional a partir de relações complexas com o meio, com outras pessoas e com os fatos.

E, completando a análise, aparecem as necessidades, dificuldades e acontecimentos que constituem o processo de desenvolvimento profissional dos professores. Nos relatos das professoras alfabetizadoras, os acontecimentos que marcaram o desenvolvimento profissional foram momentos charneiras na profissão, pois expressam as transformações ocorridas, resultado de relações estabelecidas com o grupo de trabalho ou com a instituição. Foram selecionados acontecimentos transformadores dessas professoras:

Rachel: Fui a uma reunião na Prefeitura e a minha supervisora da escola bateu nas minhas costas e falou, orgulhosa: 'Essa menina ajudaria muito na elaboração dessa proposta'! Ela disse isso porque via a minha prática diária e resolveu brincar com a situação. Mas, no fim das contas, eles entraram em contato e me chamaram. Passei por uma sabatina bem grande sobre o que eu lia, o que eu pensava. Assim que entrei, realmente me empenhei no desafio [...] Fizemos estudos mais aprofundados [...] Nesse periodo em que estive na Secretaria, senti-me feliz e realizada. Não por estar na Secretaria de Educação, mas pelo auxílio que tivemos da UFPR na época e pela troca de experiências entre profissionais da rede.

Cora: Nessa época, fui convidada para trabalhar como alfabetizadora do Núcleo Regional de Educação, outra experiência bastante significativa e desafiadora em minha vida profissional. Fazia visitas nas escolas, trabalhando direta- mente com os professores, observando caderno de alunos, sugerindo material, estratégias e encaminhamentos para cada situação. As leituras constantes davam-nos suporte para os assessoramentos ofertados no Núcleo. O desafio estava em entrar no universo dos professores, uma vez que existia certa resistência para esse tipo de visita. Clarice: Uma das coisas que me fizeram crescer muito como profissional foi ter entrado no Município. A experiência permitiu que eu enxergasse muitas outras formas de trabalhar. $\mathrm{Na}$ escola particular, o que se avalia ou valida com a criança é bem diferente, o tempo é curto. Fora dela, percebi que sempre há o que aprender, principalmente com as crianças.

Cecilia: Em julho de 2005, eu concluí o Magistério Normal Superior. Não lembro se foi logo depois ou no ano seguinte, mas apareceu um concurso da rede municipal. Resolvi fazer a prova, passei e fui tão feliz falar para o meu chefe do centro auditivo: 'Quero a minha conta, porque agora eu vou ser professora'. Fui nomeada em fevereiro de 2007 e, na hora de escolher vaga no núcleo, optei por trabalhar na escola em que fui alfabetizada. A diretora era professora na época em que eu estudava, então, seria tudo tranquilo. A professora que eu substituiria iria sair de licença maternidade e só estavam aguardando alguém vir do concurso para assumir a turma. Era uma segunda série.

O desenvolvimento profissional dos professores é um processo que se constitui em determinado contexto, criado a partir das relações sociais de trabalho, da cultura institucional, das oportunidades e condições dadas ao professor para valorização do estatuto profissional, da escola e do ensino, como destacam Romanowski e Martins (2010). Os acontecimentos profissionais marcaram a carreira do professor e influenciaram a forma de pensar e fazer a educação escolar.

Em relação às necessidades e dificuldades, as professoras alfabetizadoras destacaram elementos que se articularam com os processos de formação profissional e pessoal. Para Rachel, a dificuldade e a necessidade estão centradas no 
trabalho com o ato de ler e conhecer a língua escrita e concepção sobre o que aprender, enquanto professores alfabetizadores.

Destacou-se relatos que direcionam a questão levantada:

Rachel: Sinto que o alfabetizador tem carência de dois grandes conteúdos: saber o que é a língua escrita e ser um leitor. Quando o professor dá a devida importância para a língua escrita e sabe o que ela verdadeiramente é, considero - o como 50\% bom alfabetizador. Mas, para ser $100 \%$, é preciso ler. Outra questão, que pode ser até um pouco periférica, é a relação entre a concepção de aprendizagem, maturidade e idade como pré-requisitos para a criança aprende. Se o professor acha que aquele menino não está no tempo de aprender ou se alfabetizar porque ele 'é pequeno', esse professor não entende o desenvolvimento humano e, na minha opinião, isso deixa tudo bem complicado.

A professora Cora destaca as dificuldades relacionadas às condições de trabalho, à questão da aprendizagem, à articulação entre a educação infantil e o primeiro ano do ensino fundamental, decorrentes de acontecimentos gerados no contexto da escola. Indica que tornar-se um pesquisador e leitor é uma necessidade enquanto professora alfabetizadora:

Cora: Considero que muitos fatores interferem no processo, mas é extremamente angustiante para o professor alfabetizador receber crianças de cinco anos, que tiveram pouco contato com leitura e escrita, que não sabem segurar lápis corretamente, não diferenciam lápis de escrever do lápis de cor e apresentam dificuldades sérias de fonoarticulação, com a expectativa de que, ao final do ano letivo, esses alunos estejam alfabetizados. Isso sem falar nas crianças que necessitam de encaminhamentos específicos, pois não são avaliadas no primeiro ano sob a justificativa de que não apresentam habilidades neurológicas para tal.

Precisa ser um profissional pesquisador - mas não daqueles que abrem o site e imprimem atividades porque acharam 'bonitinhas'. O professor tem que saber o que a atividade pede, quais os objetivos, qual é o conteúdo que está explorando e o que se cobra do aluno ao trazer uma atividade assim. É preciso saber quando elaborar suas próprias atividades e conhecer a tecnologia, senão, os pequenos dão de duzentos a zero em você.

A partir dos relatos, é possivel observar entre Rachel e Cora o olhar sobre a aprendizagem das crianças que iniciam a alfabetização, revelando as concepções sobre o processo que incidem sobre o fazer pedagógico. Nota-se que as experiências em sala de aula, como explicou Martins (2002), são importantes para que o processo de ensino se articule com as necessidades dos alunos e, dessa maneira, a professora reavalie, redefina e reorganize suas práticas, demandando outras necessidades para o desenvolvimento profissional. Como afirmou Martins (2002, p.82): “É a partir dos problemas postos pela prática social que se geram novos conhecimentos, permitindo redefinir a própria prática".

As necessidades e dificuldades evidenciadas pelas professoras Clarice e Cecília seguiram um percurso semelhante, mas a formação destacada é aquela que apresenta práticas que permitiram agir em sala de aula e solucionar questões relacionadas à alfabetização dos alunos, como demonstraram os relatos:

Clarice: Um bom profissional é aquele que estuda $e$ se atualiza constantemente. Mas acredito que as responsáveis pelo Pacto deveriam trabalhar mais com as atividades e trazer mais aplicações - essa tinha sido minha expectativa. Outra questão é a possibilidade de fazer dinâmicas diferenciadas. Sinceramente, nem todos os cursos que a Secretaria oferece são totalmente aproveitados; já fui a cursos que não me agregaram nada $e$ penso que isso poderia ser revisto.

Outro ponto que destaco é o acompanhamento familiar. No meu caso, nem todas as famílias são comprometidas em ver a evolução da criança, mas é preciso entrega, participação efetiva. Encaminhamentos e diagnósticos demorados também precisam mudar. Queremos retorno, 
algo que possa ser usado em tempo hábil com a criança.

Cecilia: A formação com o Pacto Nacional pela Alfabetização na Idade Certa, nos últimos anos, tem ajudado bastante. Eu e a Marcia somos assim: vamos ao curso, gostamos da indicação do livro e, na semana seguinte, já estamos comprando, porque queremos colocar o encaminhamento e as nossas ideias em ação.

Não concordo com a maneira com que os alunos chegam ao terceiro ano, e não é nem questão de querer achar um culpado. A partir do momento em que aquele aluno é meu, independentemente do professor do segundo, do primeiro ou lá da educação infantil, eu tenho que dar conta do recado.

Neste momento, Martins (2002) concedeu embasamento necessário para compreender que as professoras relataram a busca de alternativas para os problemas gerados na prática e a ausência de instrumentos teóricos, limitando as análises do plano político em que o trabalho de professoras está inserido e as concepções sobre ensino e aprendizagem que as constituem, resultado dos anos de formação prescritiva pelos quais passamos.

A professora Cecília apresentou uma questão importante sobre o trabalho com a equipe escolar:

Cecília: Mas existe uma falha na própria equipe pedagógica dentro da escola. Às vezes, o ano inteiro passa e ninguém olha o que foi feito na sala de aula ou as anotações do diário. Ninguém senta e diz: 'Deixa eu ver o que você trabalhou com essa criança'.

Segundo Marcelo Garcia (1999), o desenvolvimento profissional dos professores está sujeito às pressões e influências advindas de diferentes instâncias, entre elas, forças sociais exercidas pelas famílias e pela cultura organizacional, constituindo fatores motivadores e alienantes em relação ao compromisso com a profissão, com as atividades e com modalidades de formação.
Os acontecimentos, necessidades e dificuldades das professoras alfabetizadoras forneceram pistas sobre as atividades e as condições de formação e organização do trabalho pedagógico não apenas da sala de aula, mas em toda a escola e, consequentemente, para o desenvolvimento profissional.

\section{Considerações sobre o desenvolvimento profissional de professoras alfabetizadoras}

Estudar o desenvolvimento profissional de professoras alfabetizadoras foi um trabalho de "experimentar a própria experiência", como afirmou Thompson (1981), pois o tema encaminha para reflexões sobre os acontecimentos, formações, práticas e pessoas de referência em diferentes períodos na carreira. Faz relembrar e tomar consciência dos sentimentos, da cultura e dos valores que compõe o ser e o fazer de um professor.

Para chegar ao nivel compreensivo sobre o processo de desenvolvimento profissional, foi necessário refletir sobre determinadas questões que se originam e habitam as instituições de ensino, percorrendo tempos/espaços e buscando encontrar as relações determinadas no grupo social.

As histórias de vida e formação não são lineares e apresentam muitos elementos que possibilitam compreender como as professoras pensam e porque agem de determinadas maneiras diante de algumas situações de sala de aula ou da própria escola. Buscar as pistas não foi uma tarefa fácil - mas cada nova leitura, palavras e frases dos depoimentos indicaram elementos importantes para o desenvolvimento profissional.

Um dos primeiros dados que as histórias de vida trouxeram foram os laços de parentesco (JOSSO, 2006) que percorrem etapas significativas da formação. São as relações estabelecidas 
no grupo familiar, que as auxiliam no processo de alfabetização e são as primeiras forças a alavancar a tomada de decisão na profissão. São seguidas pelas forças produzidas pelo modelo de trabalho imposto ao magistério pela sociedade, que vê a docência como atividade feminina - pois a mulher pode cuidar e ensinar ao mesmo tempo - e pelas forças de um modelo de produção, no qual a mulher advinda da família de classe trabalhadora encontrará na sala de aula a melhoria do padrão social.

A atuação profissional na RME de Curitiba com turmas de alfabetização ocorre para as professoras Rachel, Cora, Clarice e Cecília devido à cultura organizacional, que há anos faz um direcionamento dos profissionais para uma determinada vaga em uma determinada escola, e não para uma determinada função dentro do quadro de professores. Na sequência das narrativas, as professoras alfabetizadoras trouxeram referências aos alunos, indicando que laços geracionais se estabelecem também como um elemento marcante no desenvolvimento profissional.

No desenvolvimento profissional das professoras alfabetizadoras, os laços profissionais são indicativos de elementos que marcam o processo. As relações estabelecidas a partir desses laços são singulares e se constituem pela presença de alguém para debater, questionar e receber orientações. Considerou-se esse laço de fundamental importância no processo de desenvolvimento, pois a presença de outro profissional que analise as necessidades, acompanhe as dificuldades, oriente e auxilie no redimensionamento da prática pedagógica possibilita transformações no fazer do professor. Estaria aí o princípio de um modelo de formação continuada sustentado pelo apoio profissional mútuo.

Nas narrativas, encontraram-se os elementos indicados como laços contextuais da profissão, que abrangeram os acontecimentos, necessidades e dificuldades da trajetória profissional. Esses laços marcaram os momentos de transformação no desenvolvimento profissional, foram constituídos nas e pelas relações estabelecidas no grupo, moveram o professor como profissional que possui concepções, crenças e valores e, concomitantemente, moveram enquanto pessoa que pertence a um grupo que faz, pensa, reflete, organiza e recria o ambiente da escola.

Alguns laços contextuais da profissão indicaram as transformações ocorridas na carreira e que marcaram o desenvolvimento profissional, como a participação na função de formadora, enquanto outros apontam para necessidades e dificuldades originadas no ambiente da escola - situações em que as professoras solicitaram apoio, pois as formações inicial e continuada ainda não forneceram elementos suficientes para a compreensão do trabalho com famílias - e as demandas que apresentam para a alfabetizadora -, a inclusão e a escola como espaço formativo.

Os dados da pesquisa demonstraram que o desenvolvimento profissional de professoras alfabetizadoras se constitui como uma malha, na qual o professor sustenta fazeres, ideias, concepções, crenças, valores, experiências. É um processo interlaçado pela prática, pela formação inicial e continuada, por acontecimentos pessoais e profissionais, por aprendizagens representativas do momento histórico e social da educação, além dos conhecimentos, necessidades, dificuldades e momentos da trajetória profissional em diferentes contextos de atuação, que produzem, ao longo do tempo, laços a partir das relações estabelecidas em diferentes grupos sociais.

\section{REFERÊNCIAS}

ABRAMOWSKI, Ana. Maneras de querer: los afectos docentes en las relaciones pedagógicas. Buenos Aires: Paidós, 2010. 
ACEVEdO, Maria José; VOLNOVICH, Juan Carlos. El Espacio Institucional. Buenos Aires: Lugar Editorial, 1991.

BARDIN, Laurence. Análise de conteúdo. Lisboa, Portugal: Edições 70, 2010.

DAY, Christopher. Desenvolvimento profissional de professores. Os desafios da aprendizagem permanente. Porto: Porto Editora, 2001.

FENSTERMACHER, Gary. e BERLINER, David. (1985). Determining the value of staff development. Elementary School Journal, 85 (3): 281-314.

FREIRE, Paulo. A educação na cidade. São Paulo: Cortez, 1991.

GATTI, Bernadete Angelina. Os Professores e Suas Identidades: o desenvolvimento da heterogeneidade. Cadernos de Pesquisa, Fundação Carlos Chagas, São Paulo, n. 98, p. 85-90, ago. 1996. Disponível em: http:/ / publicacoes.fcc.org.br/ojs/index.php/cp/article/view/798/809 Acesso em: 10 mar. 2020

GATTI, Bernadete Angelina.; BARRETO, Elba Siqueira. Professores: aspectos de sua profissionalização, formação e valorização social. Brasília, DF: UNESCO, 2009.

HOÇA, Liliamar. Desenvolvimento Profissional de Professoras Alfabetizadoras. 2017. 215f. Tese (Doutorado em Educação). Programa de Pós Graduação em Educação. Pontificia Universidade Católica do Paraná (PUC/PR), Curitiba, 2017.

HUBERMAN, Michël. O ciclo de vida profissional dos professores. In: NÓVOA, Antônio. Vidas de Professores. Porto: Porto Editora, 2007. p. 31-61.

JOSSO, Marie-Christine. Experiências de vida e formação. 2a edição. Natal, RN: EDUFRN; São Paulo: Paulus, 2010.
JOSSO, Marie-Christine. A transformação de si a partir da narração de histórias de vida. Educação, Porto Alegre, v. 3, n. 63, p. 413-438, set/dez. 2007. Disponível em: <http://wp.ufpel.edu.br/gepiem/ files/2008/09/a_tranfor2.pdf>. Acesso em: 23 set. 2015.

LOURO, Guacira Lopes. Mulheres nas salas de aulas. In: Priore, Mary Del. (org.) História das mulheres no Brasil. 10a ed. São Paulo: Contexto, 2015. p. 443-481.

MARCELO GARCIA, Carlos. Formação de Professores: para uma mudança educativa. Porto: Porto Editora, 1999.

MARCELO GARCIA, Carlos. El professorado principiante: Inserción a la docencia. Barcelona: Ediciones Octaedro, S.L, 2009.

MARTINS, Pura Lúcia Oliver; ROMANOWSKI, Joana Paulin. Formação continuada: contribuições para o desenvolvimento profissional dos professores. Rev. Diálogo Educacional, Curitiba, v. 10 , n. 30, p. 285300, maio/ago, 2010. Disponível em: <http://www2. pucpr.br/reol/pb/index.php/dialogo?dd1=3607\&dd99=view\&dd98=pb>. Acesso em: 15 jul. 2015.

MARTINS, Pura Lúcia O. Didática teórica/didática prática: para além do confronto. 7a ed., São Paulo: Loyola, 2002.

NIAS, Jennifer. Changing Times, Changing Identities: Grieving for a Lost Self. Educational Research and Evaluation [ed. R. Burgess]. Lewes: The Falmer Press, 1991.

Thompson, edward Palmer. A miséria da teoria ou planetário de erros. Rio de Janeiro: Zahar Editores, 1981.

Recebido em: 26/10/2019 Revisado em: $12 / 07 / 2020$ Aprovado em: $28 / 07 / 2020$

Liliamar Hoça é doutora e mestre em educação pela Pontifícia Universidade Católica do Paraná (PUCPR); graduada em Pedagogia. Pesquisadora integrante do grupo Práxis Educativa-Dimensões e Processos da PUCPR, professora universitária Universidade Cesumar (UniCesumar), pedagoga da Rede Municipal de Ensino (RME) de Curitiba, exercendo a função de diretora do Centro Municipal de Atendimento Educacional Especializado Ronaldo Vadson Schwantes, em Curitiba (PR).E-mail: liliamarho@gmail.com 